\title{
TENS effects on dysesthesia and quality of life after breast cancer surgery with axilectomy: randomized controlled trial
}

\author{
Efeitos da TENS na disestesia e qualidade de vida após \\ cirurgia de câncer de mama com finfadenectomia \\ axilar: estudo controlado randomizado
}

\begin{abstract}
Andreza Carvalho Rabelo Mendonça, Mariana Tirolli Rett, Priscila de Araújo Garcez, Maria Jane das Virgens Aquino, Lucas Vasconcelos Lima, Josimari Melo DeSantana*
\end{abstract}

Universidade Federal de Sergipe (UFS), São Cristóvão, SE, Brazil

\begin{abstract}
Introduction: After breast cancer surgery, many women may present quality of life (QOL) impairment due to the presence of discomfort as dysesthesia in the anterolateral region of the chest, armpit and/or medial part of the arm caused by intercostobrachial nerve injury (ICBN). Objective: To investigate the effects of Transcutaneous Electrical Nerve Stimulation (TENS) on dysesthesia intensity at the intercostobrachial nerve (ICBN) dermatome and QOL in women after breast cancer surgery. Methods: A randomized, double-blinded, placebo controlled clinical trial was conducted. Women undergoing axillary lymphadenectomy (AL), with dysesthesia on ICBN dermatome were included. Patients were divided into active and placebo TENS groups. TENS was applied with a frequency of $100 \mathrm{~Hz}$, pulse duration of $100 \mu \mathrm{s}$ and amplitude at the highest sensory intensity tolerable for 20 minutes during 20 sessions, three times a week, on alternating days. In the placebo TENS group, electrical current was delivered only during the first 45 seconds of application. Skin sensitivity was assessed by
\end{abstract}

\footnotetext{
ACRM: Doctoral student, e-mail: andrezinharabelo@yahoo.com.br MTR: PhD, e-mail: marianatrb@gmail.com PAG: Doctoral student, e-mail: prix_garcez@hotmail.com MJVA: Master's student, e-mail: mjvafisio@gmail.com LVL: Doctoral student, e-mail: lucasso@hotmail.com JMS: PhD, e-mail desantanajm@gmail.com
} 
esthesiometry. Dysesthesia intensity was assessed with a visual analogue scale (VAS) and QOL with the EORTC QLQ-C30 and the specific EORTC QLQ-BR23 which is the Breast Cancer Module. Results: VAS decreased significantly over the 20 sessions in the active TENS group $(\mathrm{p}<0.006)$ and no difference was found between groups. There weren't significant differences in EORTC QLQ-C30 and EORTC QLQ-BR23 after 20 sessions or between groups. Conclusion: TENS decreased dysesthesia intensity in the ICBN dermatome after breast cancer surgery, but did not improve quality of life.

Keywords: Breast Cancer. Transcutaneous Electrical Nerve Stimulation (TENS). Paresthesia. Quality of life (QOL). Pain.

\section{Resumo}

Introdução: Após cirurgia para câncer de mama, muitas mulheres podem apresentar prejuízo na qualidade de vida (QV) pela presença do desconforto como disestesia na região anterolateral do tórax, axila e/ou parte medial do braço, causada pela lesão do nervo intercostobraquial (NICB). Objetivo: Investigar os efeitos da Estimulação Elétrica Nervosa Transcutânea (TENS) na intensidade da disestesia no dermátomo do NICB e na QV após cirurgia de câncer de mama. Métodos: Ensaio clínico, controlado, randomizado, duplo-cego. Mulheres submetidas à linfadenectomia axilar (LA), com disestesia no dermátomo do NICB foram distribuídas em: TENS placebo e TENS ativo (um par de eletrodos autoadesivos) no trajeto do NICB, frequência de $100 \mathrm{~Hz}$, duração de pulso de $100 \mu \mathrm{s}$, e amplitude no limiar sensorial máximo tolerado pela paciente, por 20 minutos, durante 20 sessões, três vezes na semana. A sensibilidade da pele foi avaliada através da estesiometria e foi considerada disestesia a partir do terceiro monofilamento $(2,48 \mathrm{~g})$. A intensidade da disestesia foi avaliada através da Escala Visual Analógica (EVA) e a QV com o EORTC QLQ-C30 e o EORTC QLQ-BR23. Resultados: A intensidade da disestesia diminuiu significativamente ao longo das 20 sessões no grupo TENS ativa $(p<0,006)$, mas não houve diferença entre os grupos. Não houve diferenças significativas na QV após as 20 sessões entre os grupos. Conclusão: A TENS foi capaz de diminuir a intensidade da disestesia no dermátomo do NICB, mas não melhorou a qualidade de vida.

Palavras-chave: Câncer de mama. Estimulação Elétrica Nervosa Transcutânea (TENS). Parestesia. Qualidade de Vida (QV). Dor.

\section{Introduction}

Breast cancer is a highly prevalent disease among women and its treatment can have negative repercussions on physical, social, family, emotional and work-related aspects. The main complications are limitation of ipsilateral shoulder range of motion, scar adhesion, seroma, dehiscence, lymphedema, dysesthesia and/or pain in the shoulder, axillary and lateral chest wall [1-3]. Thus, survivors of this disease may experience impairments in quality of life (QOL), functionality and the ability to perform day-to-day tasks [1-6].

Chronic localized or regional discomfort, including dysesthesia, hypoesthesia, paresthesia and pain, after breast cancer surgery is a common and well-recognized problem with prevalence rates ranging from 20 to $65 \%$ [4]. This is a clinical situation that influences on their physical functioning, mood, work, relationships, sleep and QOL, but it has not been investigated. Post-mastectomy pain syndrome (PMPS) is defined as chronic pain for over a 3-month period $[2-5,7]$ PMPS is different from other painful syndromes because it is typically localized in axillary region and/or medial arm and anterior or lateral region of the chest, causing pressure sensation or numbness, burning and/or shooting pain $[2-4,7]$. It is caused by either primary lesion or dysfunction in the nervous system and is considered a neuropathic condition that arises after surgical treatment for breast cancer. This can occur due to intercostobrachial nerve (ICBN) lesion, neuroma and lesions of other nerves [3]. 
Taking into account complications after surgery, healthcare professionals must understand the impact of breast cancer treatment on the patient's QOL in order to promote a better health pattern. Health-related quality of life is a multidimensional concept that characterizes individual's total well-being and includes psychological, social and physical dimensions. In this context, the rehabilitation can alleviate post-treatment side effects, maintain QOL and improve the survival $[4,5]$. The Transcutaneous Electrical Nerve Stimulation (TENS) has been widely used to alleviate pain [8,9]. In the case of neuropathic pain [10], its effect has been studied in trigeminal neuralgia [11], shingles [11], diabetic neuropathy [12], among others [13], but information about dysesthesia approach among patients after breast cancer surgery remains scarce.

TENS is an easy to apply, low cost, non-invasive therapy without side effects, which has already showed good results on reducing other types of neuropathic pain [9-12], because it promotes a sensory stimulus that activates $A \beta$ afferent fibers and, consequently activates inhibitory descendent pathways, reducing central nociceptive cellular activity [9-14]. And peripherally, at the application place, opioid and $\alpha-2$ noradrenergic receptors are involved in TENS induced analgesia $[15,16]$.

To date, no studies with TENS application for complaints of sensitivity-related discomfort have been found in the available literature, specifically on the path of ICBN after surgery for treatment of breast cancer. In addition, assessing healthrelated quality of life has been recommended in several clinical situations $[17,18]$ And in women undergoing surgical treatment for breast cancer, this evaluation may reflect how some functional limitations and the presence of symptoms in the homolateral limb may interfere with the daily life of these $[3,5]$.

Considering that ICBN dermatome dysesthesia causes a discomfort that compromises daily activities and consequently quality of life, it becomes relevant to investigate a new form of therapeutic intervention to minimize such discomfort. Thus, the objective of this study was to investigate the effect of TENS on dysesthesia intensity at the ICBN dermatome and quality of life of women after breast cancer surgery associated with AL.

\section{Methods}

\section{Study design}

Double-blind randomized placebo-controlled clinical trial.

\section{Study Population}

Women who underwent breast cancer surgery associated with AL of the three levels of lymph nodes, for more than 3 months and with a report of alteration of cutaneous sensibility at the ICBN dermatome, were included in the study. The exclusion criteria were: 1) Other underlying systemic diseases; 2) previous experience with TENS, 3) Contraindication for TENS use and 4) current use of antidepressants, psychoactive drugs and glucocorticosteroids.

Patients were randomly assigned at a 1:1 rate in two groups: Placebo TENS and Active TENS. The required sample for dependent groups was estimated at a significance level of $5 \%$ and power of $95 \%$, Standard error of the mean corresponding to 1.2 and 1.5 , and minimum difference between groups assumed as 2 of 10 points considering VAS scale. Thus, a sample of 12 subjects per group was estimated. After adding 20\% considering loss of followup, the final estimation indicated around 15 participants per group. Calculation was performed by using WinPepi, version 11.65 (Portal JH Abramson, Aug 23, 2016).

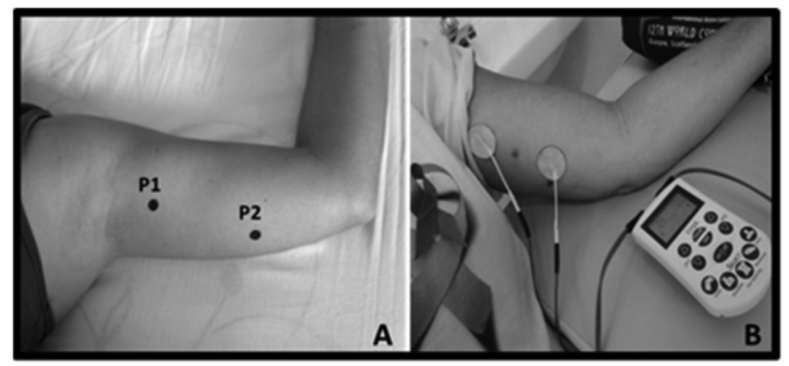

Figure 1 - A- Points of skin sensitivity assessment and TENS electrodes placement. B- TENS application at the ICBN dermatome.

The study was conducted in the Physical Therapy sector of OncoHematos at Hospital Cirurgia, city of Aracaju/SE, from the period of June 2011 to July 2012. It was approved by the Institutional Review Board of Federal University 
of Sergipe with CAEE 0095.0.107.000-11 and adequately registered in the Brazilian Registry of Clinical Trial (RBR-3s39jp).

Sample selection is described in Figure 2. Sixteen patients were allocated in each group.

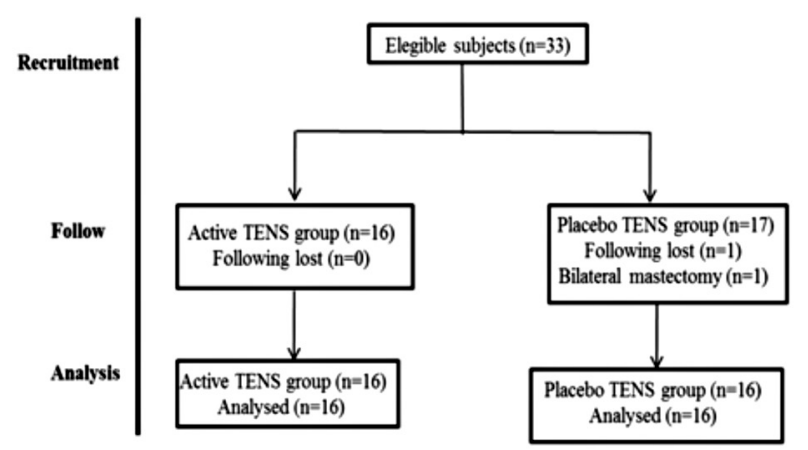

Figure 2 - Flowchart of recruitment, allocation and monitoring of patients in the different groups.

\section{Protocol}

For the stimulation, portable TENS units (Empi Select TENS, Empi Inc. ${ }^{\circledR}$, St. Paul, MN, USA) were used, after calibration by using a digital osciloscopy (TBS2000, Tektronix ${ }^{\mathrm{TM}}$, Beaverton, Oregon, EUA), which outputs a biphasic and asymmetric waveform. Stimulation parameters were set at $100 \mathrm{~Hz}$ of frequency and pulse duration of $100 \mu$ s, which are reported by the patients as a more comfortable stimulation The current intensity was raised to the maximum sensory level tolerated by the patient, which was determined by raising the amplitude of current until obtaining a visible motor contraction and reducing it until the contraction dissipates. Two circular auto adhesive electrodes $(3.2 \mathrm{~cm} 2)$, were fixed at $\mathrm{P} 1$ and $\mathrm{P} 2$ points of the ICBN dermatome (Figure 1). However, in the placebo TENS group, the device's internal circuitry was modified by the manufacturer to interrupt electrical current transmission after 45 seconds of stimulation, characterizing the new method of placebo TENS [19]. Subjects were instructed that the current sensation could or not last through the whole session but that would not influence the analgesia. TENS was applied for 20 minutes, three times per week, on alternate days, during 20 sessions. Duration and place of stimulation were the same for both groups. All patients were under a conventional physical therapy program.

Investigator 1 was responsible for patient assessment of all variables, before and after
TENS treatment. Investigator 2 performed TENS administration in all sessions. None of the researchers knew in which treatment group the patient was allocated. This procedure ensured that the study was double blind (neither the patient nor the researchers knew which treatment was being administered).

\section{Measurements}

Skin sensitivity

Skin sensitivity was assessed by using esthesiometry through the Semmer Weinstein esthesiometer (Sorri ${ }^{\circledR}$, Bauru, SP, Brazil) at two points of ICBN dermatome (Figure 1). It was considered dysesthesia when the patient noticed stimulation only from the third monofilament (purple color $-2.48 \mathrm{~g}$ ).

\section{Dysesthesia Intensity}

Visual analogue scale (VAS) was used to assess dysesthesia intensity on the intercostobrachial nerverelated dermatome. A horizontal line, $100 \mathrm{~mm}$ in length, with the left end $(0 \mathrm{~mm})$ representing "no discomfort" and the right end $(100 \mathrm{~mm})$ representing "worst discomfort". Patients were instructed to express their discomfort by marking the point in the line which represents their discomfort at the moment. The score was determined by measuring the distance in $\mathrm{mm}$ from the left end to patient mark. This test was performed from the first until the last session, before and after each TENS application.

\section{Quality of life (QoL)}

Translated version of the European Organization for Research and Treatment of Cancer Quality of Life Questionnaire- EORTC QLQ-C30 and breast cancer module - EORTC QLQ-BR23 questionnaires were employed before and after 20 sessions [20].

The EORTC QLQ-30 measures QOL and general status of health in a score called Global Health Status (GHS), allowing values in a range from 0 to 100 . Therefore, high scores represent a high QOL and, oppositively, low scores a low one. Five functional scales measure body, role, and emotional, cognitive and social function of patients. Additionally, the questionnaire includes three symptom scores (fatigue, emesis and pain) and six further singleitem symptom scores (dyspnea, insomnia, appetite loss, constipation, diarrhea and financial difficulties) which may occur in breast cancer patients. 
The EORTC QLQ-BR23, the breast cancer module, incorporates four symptom scales (systemic therapy side effects, breast symptoms, arm symptoms, upset by hair loss) and four functional scales (body image, sexual functioning, sexual enjoyment, future prospects). All these scales have four scoring possibilities, ranging from 1 (not at all) to 4 (very often). A high score presents a large amount of symptoms [20-22].

\section{Statistical analysis}

Collected data was transferred to a spreadsheet in Excel for Windows 2007 and, subsequently to the software Statistica, version 6.0. Absolute and relative frequencies, measures of central tendency (mean and median) and dispersion (standard diviation and minimum and maximum value) were used for descriptive analysis of the data. Shapiro Wilk normality test was applied, and since the data were not normally distributed, nonparametric tests were undertaken in all analyzes, with statistical significance set at $p<0.05$. To compare the intensity of dysesthesia over the 20 sessions, the Friedman test for repeated measures was applied adjusted by the Tukey test, and to comparisons between groups, Mann Whitney test was adopted. The value considered for VAS was the delta - the difference between the initial and final values. The variables of EORTC QLQ30 and EORTC QLQ BR-23 were compared before treatment initiation and after the 20th session with the Wilcoxon Matched Pairs and between groups with the Mann Whitney test. For comparison of ratio, the chi-square or Fisher's exact test was used.

\section{Results}

Regarding personal, demographic and surgical characteristics, no significant differences were found between the groups (see Table 1).

Table 1 - Personal, clinical and surgical treatment-related characteristics of Active TENS $(n=16)$ e Placebo TENS $(n=16)$ groups

\begin{tabular}{|c|c|c|c|c|c|}
\hline \multirow{3}{*}{$\begin{array}{l}\begin{array}{c}\text { Personal, clinical and surgical } \\
\text { characteristics }\end{array} \\
\text { Age (years) }\end{array}$} & \multicolumn{4}{|c|}{ Active TENS / Placebo TENS } & \multirow{3}{*}{$\begin{array}{c}p \\
0.45\end{array}$} \\
\hline & \multicolumn{2}{|c|}{ Mean $( \pm$ STDEV) } & \multicolumn{2}{|c|}{ Median (min/max) } & \\
\hline & $50.37( \pm 8.11)$ & $52.12( \pm 7.80)$ & $54(40 / 62)$ & $54(40 / 62)$ & \\
\hline Weight (kg) & $68.00( \pm 10.43)$ & $69.60( \pm 10.59)$ & $69(48 / 85)$ & $69(48 / 85)$ & 0.47 \\
\hline Height (m) & $1.54( \pm 0.04)$ & $1.56( \pm 0.06)$ & $1.56(1.45 / 1.7)$ & $1.56(1.45 / 1.7)$ & 0.37 \\
\hline \multirow[t]{2}{*}{ BMI $\left(\mathrm{kg} / \mathrm{m}^{2}\right)$} & $28.81( \pm 4.98)$ & $28.04( \pm 4.77)$ & $29.71(19.33-34.9)$ & $29.71(19.33-34.9)$ & 0.88 \\
\hline & $n(\%)$ & $\mathrm{n}(\%)$ & & & \\
\hline \multicolumn{6}{|l|}{ Educacional level } \\
\hline High school and college & $3(18.75)$ & $10(62.5)$ & - & - & \multirow{2}{*}{0.14} \\
\hline Elementary and illiterate & $13(81.25)$ & $6(37.5)$ & - & - & \\
\hline \multicolumn{6}{|l|}{ Marital status } \\
\hline Single/Widow & $7(43.75)$ & $11(68.75)$ & - & - & \multirow{2}{*}{0.15} \\
\hline Married & $9(56.25$ & $5(31.25)$ & - & - & \\
\hline \multicolumn{6}{|l|}{ Occupation } \\
\hline Housewife, cooky, general servisse & $10(62.50)$ & $12(75.00)$ & - & - & \multirow{2}{*}{0.35} \\
\hline Peasant & $6(37.50)$ & $4(25.00)$ & - & - & \\
\hline \multicolumn{6}{|l|}{ Surgery type } \\
\hline Mastectomy & $11(68.75)$ & $13(81.25)$ & - & - & \multirow{2}{*}{0.41} \\
\hline Quadrantectomy & $5(31.25)$ & $3(18.75)$ & - & - & \\
\hline \multicolumn{6}{|l|}{ Surgery Side } \\
\hline Right & $5(31.25)$ & $5(31.25)$ & - & - & \multirow{2}{*}{1.00} \\
\hline Left & $11(68.75)$ & $11(68.75)$ & - & - & \\
\hline
\end{tabular}


Table 1 - Personal, clinical and surgical treatment-related characteristics of Active TENS $(n=16)$ e Placebo TENS $(n=16)$ groups

\begin{tabular}{|c|c|c|c|c|c|}
\hline $\begin{array}{c}\text { Personal, clinical and surgical } \\
\text { characteristics }\end{array}$ & \multicolumn{4}{|c|}{ Active TENS / Placebo TENS } & $p$ \\
\hline \multicolumn{6}{|l|}{ Radiotherapy } \\
\hline No & $5(31.25)$ & $9(56.25)$ & - & - & \multirow{2}{*}{0.15} \\
\hline Adjuvant/Neoadjuvant & $11(68.75)$ & $7(43.75)$ & - & - & \\
\hline \multicolumn{6}{|l|}{ Chemotherapy } \\
\hline No & $1(6.25)$ & $3(18.75)$ & - & - & \multirow{2}{*}{0.59} \\
\hline Adjuvant/Neoadjuvant & $15(93.75)$ & $13(81.25)$ & - & - & \\
\hline \multicolumn{6}{|c|}{ Mean $( \pm S D)$} \\
\hline Radiotherapy (number sessions) & $32.00( \pm 9.36)$ & $25.71( \pm 6.77)$ & $30(25 / 60)$ & $28(25 / 60)$ & 0.07 \\
\hline Chemoterapy (number sessions) & $7.68( \pm 6.86)$ & $5.68( \pm 4.49)$ & $4.5(0 / 28)$ & $4(0 / 16)$ & 0.54 \\
\hline Lymph nodes removed & $14.18( \pm 5.75)$ & $13.87( \pm 7.70)$ & $15.5(5 / 24)$ & $12(7 / 35)$ & 0.26 \\
\hline Lymph nodes committed & $1.87( \pm 3.96)$ & $3.62( \pm 4.14)$ & $0.5(0 / 16)$ & $3(0 / 12)$ & 0.24 \\
\hline Time of surgery (months) & $21.68( \pm 21.68)$ & $22.31( \pm 53.99)$ & $18(3 / 36)$ & $7.5(2 / 23)$ & 0.25 \\
\hline
\end{tabular}

Note: Mann-Whitney and Chi-square test or Fisher's exact for quantitative and categorical variables, respectively. There was no significant difference between groups for none of the variables. BMl: Body Mass Index $\left(\mathrm{kg} / \mathrm{m}^{2}\right), \mathrm{kg}=$ kilogram, $\mathrm{m}=$ meter.

Intensity of dysesthesia was assessed by using VAS and decreased significantly over 20 sessions in Active TENS group when compared to baseline $(\mathrm{p}<0.006)$. No significant decrease was observed in the placebo TENS group ( $\mathrm{p}<0.403)$. However, there was no difference between placebo and active TENS (Figure 3).

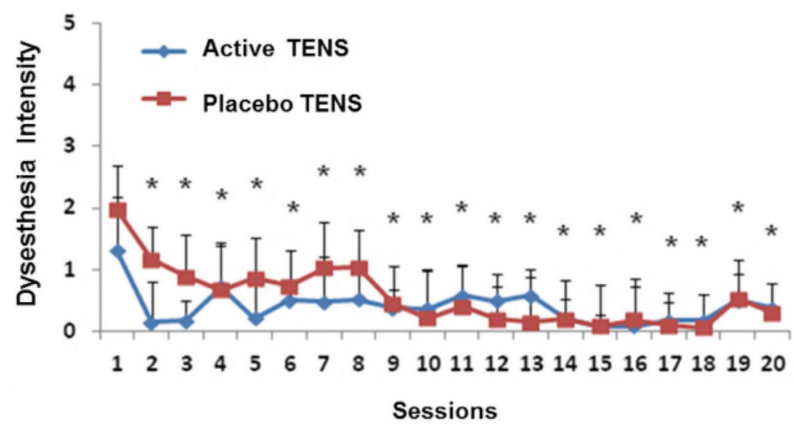

Figure 3 - Intensity of dysesthesia through the treatment sessions. ${ }^{\star} p<0.005$ for active TENS group when compared to session 1 .

No difference was observed between groups in relation to generic questions of QOL assessment.
In the active TENS group, although significant difference wasn't found, an improvement was observed in the scores of overall health, physical, emotional and social functions after the 20th session, but the same was found in the placebo TENS group (insert Table 2). In the symptom scale, pain scores, dyspnea and insomnia decreased in the Active TENS group and in the Placebo TENS group. Scores of fatigue, nausea and vomiting, pain, constipation and financial difficulties decreased. No significant differences were observed after the 20th session and between the groups.

In specific questions there were no differences between groups or after the 20th session (insert Table 2). In the Active TENS group it was found a mild improvement of all scale scores, unlike the placebo TENS group, which showed worsening of the body image, sex and sexual enjoyment scores. In the scale of symptoms, systemic therapy side effects, breast and arm symptoms decreased the scores in both groups, while hair loss scores increased, but without significant difference. 
Table 2 - Quality of life scores of EORTC QLQ-30 of Active TENS $(n=16)$ e Placebo TENS $(n=16)$ groups

\begin{tabular}{|c|c|c|c|c|c|c|c|c|}
\hline \multirow[t]{2}{*}{ EORTC QLQ-C30 Domains } & \multicolumn{2}{|c|}{ Active TENS } & \multicolumn{4}{|c|}{ Placebo TENS } & \multirow[b]{2}{*}{ pl } & \multirow[b]{2}{*}{ p2 } \\
\hline & Sessionl & Session 20 & $\mathrm{p}$ & Sessionl & Session 20 & $\mathrm{p}$ & & \\
\hline Global Health Status & $73.87 \pm 30.84$ & $74.82 \pm 25.30$ & 0.92 & $69.69 \pm 30.58$ & $64.03 \pm 16.39$ & 0.06 & 0.63 & 0.29 \\
\hline \multicolumn{9}{|l|}{ Functional Scales } \\
\hline PhysicalFunctioning & $74.58 \pm 14.41$ & $76.25 \pm 23.47$ & 0.38 & $70.83 \pm 20.34$ & $84.03 \pm 23.47$ & 0.50 & 0.63 & 0.41 \\
\hline Role Functioning & $81.25 \pm 20.06$ & $80.20 \pm 28.03$ & 0.95 & $68.75 \pm 36.95$ & $68.75 \pm 40.31$ & 0.93 & 0.57 & 0.45 \\
\hline Cognitive Functioning & $70.83 \pm 23.95$ & $68.75 \pm 31.54$ & 0.82 & $61.45 \pm 37.86$ & $65.62 \pm 36.24$ & 0.53 & 0.80 & 0.96 \\
\hline Emotional Functioning & $25.43 \pm 29.94$ & $34.42 \pm 34.42$ & 0.46 & $33.07 \pm 33.07$ & $31.76 \pm 31.76$ & 0.11 & 0.86 & 0.85 \\
\hline Social Functioning & $82.29 \pm 25.43$ & $90.62 \pm 20.15$ & 0.04 & $76.04 \pm 34.94$ & $92.70 \pm 18.22$ & 0.10 & 0.89 & 0.77 \\
\hline \multicolumn{9}{|l|}{ Symptom Scales } \\
\hline Fatigue & $22.88 \pm 25.45$ & $24.65 \pm 25.19$ & 0.80 & $31.11 \pm 28.44$ & $29.76 \pm 34.26$ & 0.62 & 0.39 & 0.72 \\
\hline Nausea and Vomiting & $13.52 \pm 25.97$ & $14.50 \pm 18.09$ & 0.61 & $14.48 \pm 20.94$ & $8.32 \pm 21.93$ & 0.39 & 0.80 & 0.13 \\
\hline Pain & $29.10 \pm 33.61$ & $22.82 \pm 32.07$ & 0.54 & $45.65 \pm 36.35$ & $30.10 \pm 34.57$ & 0.91 & 0.18 & 0.25 \\
\hline Dyspnea & $12.49 \pm 29.49$ & $10.37 \pm 26.40$ & 0.89 & $10.37 \pm 29.02$ & $10.41 \pm 29.09$ & 1.00 & 0.77 & 0.76 \\
\hline Insomnia & $39.53 \pm 36.95$ & $35.34 \pm 39.34$ & 0.68 & $33.28 \pm 43.85$ & $43.71 \pm 43.42$ & 0.12 & 0.48 & 0.51 \\
\hline AppetiteLoss & $12.48 \pm 23.93$ & $14.53 \pm 27.09$ & 0.68 & $14.58 \pm 34.35$ & $16.64 \pm 34.41$ & 0.78 & 0.85 & 0.78 \\
\hline Constipation & $22.88 \pm 33.79$ & $37.45 \pm 43.67$ & 0.20 & $22.80 \pm 31.45$ & $14.57 \pm 32.11$ & 0.34 & 0.96 & 0.16 \\
\hline Diarrhea & $2.06 \pm 8.25$ & $8.32 \pm 19.22$ & 0.28 & $8.25 \pm 14.75$ & $12.47 \pm 29.47$ & 0.68 & 0.36 & 0.98 \\
\hline Financial Difficulties & $31.15 \pm 35.36$ & $31.20 \pm 42.97$ & 0.86 & $54.11 \pm 45.35$ & $39.53 \pm 38.91$ & 0.10 & 0.13 & 0.30 \\
\hline \multicolumn{9}{|l|}{ EORTC QLQ- BR23 SCALE } \\
\hline \multicolumn{9}{|l|}{ Functional Scales } \\
\hline Body Image & $79.68 \pm 22.35$ & $84.89 \pm 23.80$ & 0.41 & $38.87 \pm 31.76$ & $32.00 \pm 32.18$ & 1.00 & 0.59 & 0.32 \\
\hline Sexual Functioning & $27.05 \pm 27.80$ & $34.30 \pm 30.05$ & 0.01 & $32.58 \pm 27.11$ & $23.32 \pm 28.98$ & 0.65 & 0.98 & 0.66 \\
\hline Sexual Enjoyment & $33.30 \pm 33.32$ & $42.31 \pm 39.65$ & 0.91 & $28.36 \pm 40.81$ & $24.91 \pm 35.82$ & 0.79 & 0.56 & 0.62 \\
\hline Future Prospects & $41.66 \pm 41.27$ & $56.25 \pm 39.84$ & 0.10 & $42.80 \pm 43.67$ & $42.30 \pm 45.49$ & 1.00 & 0.88 & 0.63 \\
\hline \multicolumn{9}{|l|}{ Symptom Scales } \\
\hline Sistemic Therapy & $33.10 \pm 16.11$ & $26.03 \pm 18.12$ & 0.14 & $38.87 \pm 29.96$ & $32.00 \pm 22.12$ & 0.19 & 0.98 & 0.41 \\
\hline Breast Symptoms & $23.31 \pm 19.94$ & $22.81 \pm 20.05$ & 0.87 & $32.58 \pm 27.49$ & $23.32 \pm 21.60$ & 0.07 & 0.31 & 0.96 \\
\hline Arm Symtoms & $32.55 \pm 24.49$ & $28.36 \pm 23.27$ & 0.47 & $28.36 \pm 18.13$ & $24.91 \pm 19.17$ & 0.48 & 0.65 & 0.93 \\
\hline Upset By Hair Loss & $14.27 \pm 26.20$ & $66.50 \pm 47.37$ & 0.03 & $42.80 \pm 46.01$ & $83.30 \pm 49.98$ & 0.35 & 0.27 & 0.63 \\
\hline
\end{tabular}

Note: Values in mean $\pm \mathrm{SD}$ (standard deviation). There was no significant differences before and after the $20^{\text {th }}$ session (Wilcoxon Matched Pairs Test) and between groups (Mann Whitney test) difference was found; p1: session 1 Active TENS x Placebo TENS; p2: session 20 Active TENS $x$ Placebo TENS.

\section{Discussion}

The presence of dysesthesia and other postoperative complications of breast cancer could adversely affect QOL. Thus, the assessment of QOL has been recommended to assess perception patients have about their own disease. In our findings, baseline results from the scales of the quality of life, specific and generic, showed scores similar to baselines of other review studies involving women with breast [20-24].
In the active TENS group, there was a slight but not significant improvement in scores of overall health, physical, emotional and social functions. Regarding specific issues, there was an improvement in active TENS-treated patients and a worsening in placebo TENS group. It is believed that the decrease in dysesthesia intensity may have reflected the improvement in those women who received the active TENS. Since it decreases the discomfort, women might experience a better QOL. However, dysesthesia intensity was not different between groups. 
Although the EORTC QLQ-C30 and QLQ-BR-23 are indicated to be used for oncological samples and has a specific module for patients with breast cancer, its domains may be targeted for different situations experienced by cancer patients and couldn't be sufficiently sensible to detect the negative role of dysesthesia on the quality of life of those patients. Thus, it is also possible that the questionnaire used in this study to measure QOL wasn't the most appropriate although it is a golden-standard tool for this proposal. A number of different questionnaires have been used to measure quality of life in breast cancer population, and maybe another questionnaire may better assess this outcome. Recently, Oliveira et al. [25] investigated the measurement properties of two generic (World Health Organization Quality of Life - bref, WHOQOL-bref, and the Medical Outcomes Study 36 - Item Short-Form Health Survey, SF-36) and one specific (Functional Assessment of Cancer Therapy - Breast plus Arm Morbidity, FACT-B+4) quality of life questionnaires for women with breast cancer. The WHOQOL-bref and FACT-B+4 showed adequacy to assess QOL in breast cancer patients in the majority of the properties examined.

Another possible reason for the lack of difference between groups in QOL scores is that the number of sessions may not have been enough to generate significant changes in the QOL [26], or some women were accustomed/adapted to the changes in sensitivity.

It is questioned whether the fact that the patients were subjected to the treatment with TENS in a later phase of NCIB injury and not in an acute phase of recovery would influence our findings. In the early phase after surgeries, there is the neuroplasticity phenomena and perhaps a better response to improve sensory perception can be targeted in this stage of recovery [27]. But active TENS was satisfactory to decrease dysesthesia intensity on the NICB dermatome. This type of sensitivity disturbance, besides being characterized as discomfort, can also be reported by some patients as a painful, burning and or tingling sensation. The use of TENS for dysesthesia management was not found in the available literature, but its analgesic effects on peripheral nerve injuries have been demonstrated in both experimental animal studies [14, 28, 29] and human studies, showing hypoalgesic effects on neuropathic-like pain such as trigeminal neuralgia, herpes zoster, diabetic neuropathy and neuropathic pain of spinal cord injured individuals [10-13].

In some studies, treatment protocols ranged from 10 to 20 applications of active TENS and sensitivity was enhanced, as TENS increased the cutaneous threshold in all of them $[6,9]$. Maybe because TENS is an electroanalgesic resource of sensory modality that works directly in the central nervous system by activation of primary $A \beta$ afferent fibers and promotes a reduction in the central nociceptive cell activity $[8,9]$. In the clinical practice, the approach of sensory peripheral nerve injuries that have been proposed were dermal desensitization using apparatuses of different textures and temperature applied to ICBN dermatome, but only lymphatic drainage showed positive results to reduce dysesthesia [30, 31].

It was also found that the placebo TENS group decreased the intensity of dysesthesia but without significant difference. The literature suggests that there are positive effects of placebo TENS [32], as this is a part of the overall therapeutic action, beyond the expectation of response, which is the probability of a procedure or agent to promote pain relief. Thus, if the individual has an expectation of pain reduction after administration of placebo treatment, it is sufficient to generate pain relief [32].

Placebo response induced by analgesia expectations activates a number of central chemical mediators such as dopamine and endogenous opioids. The placebo effect is a psychobiological phenomenon characterized by the response of a subject to a substance or procedure known to have no therapeutic effect [12]. The placebo method may affect a wide variety of subjective, behavioral and physiological responses [13] and may be related to an expectation of clinical improvement $[14,16,18]$.

There's a growing interest in the study of placebo effects. The study of this effect reflects current thinking in neuroscience, the idea that subjective constructions as expectations have identifiable physiological bases which are powerful modulators at motor, perceptual and homeostatic processes level [14].

Different expectations promote several analgesic effects, which can be used in clinical practice [20], such as the possibility of achieving 
favorable pharmacological effects without the intake of drugs [21]. Pharmacological studies revealed that placebo analgesia was shown to be influenced by the type of expectation given for pain relief [20, 22, 23]. Motor responses seem to be mediated by verbally induced expectations. Furthermore, expectations that induce analgesia or hyperalgesia influence the relief or increase of pain, respectively [24]. It is believed that conscious physiological processes, such as pain and motor performance, are mediated by the expectation, however, unconscious physiological functions, such as hormone secretion is mediated by placebo [14].

Although no differences between the groups were observed, the effects of TENS on peripheral nerve injuries should be valued. Given that breast cancer is the most common in the female population, many women will undergo surgical procedures and may have alterations on sensitivity with the symptom of ICBN dermatome dysesthesia, the use of active TENS may represent a therapeutic option. This study is the first to suggest the use of TENS in this patient profile and this may represent a tool to relieve this discomfort [30].

Although the use of TENS did not bring additional effects on the QOL, it highlights the importance of evaluating it in clinical practice as it assists in the development of therapeutic strategies for the physical and functional complications.

\section{Conclusion}

Although not different from placebo, according to the methods used in the research, TENS could decrease dysesthesia intensity in the ICBN dermatome after breast cancer surgery, but did not improve the quality of life. Placebo effects might have been potentialized by the method use, which includes a brief active stimulation. These results may help clinicians and researchers in approaching oncology patients who have such altered cutaneous sensitivity. However, new protocols or different types of therapeutic electric currents can be employed in the search for positive repercussions on quality of life, since the physical and sensory functionality of the limb is important for women to perform their daily activities.

\section{References}

1. Ewertz M, Jensen AB. Late effects of breast cancer treatment and potentials for rehabilitation. Acta Oncol. 2011;50(2):187-93.

2. Vilholm OJ, Cold S, Rasmussen L, Sindrup $\mathrm{SH}$. The post mastectomy pain syndrome: an epidemiological study on the prevalence of chronic pain after surgery for breast cancer. Br J Cancer. 2008;99(4):604-10.

3. Assis MR, Marx AG, Magna LA, Ferrigno ISV. Morbidade tardia na função do membro superior e na qualidade de vida de mulheres pós cirurgia de câncer de mama. Braz J Phys Ther. 2013;17(3):236-43.

4. Noh DY, Nam SJ, Ahn SH, Park BW, Lee ES, Lee MK, et al. Association of clinical experiences with patientreported outcomes among breast cancer surgery patients: breast cancer quality care study. Qual Life Res. 2008;17(2):215-25.

5. van Weert EV, Hoekstra-Weebers JE, Grol BM, Otter $\mathrm{R}$, Arendzen JH, Postema K, et al. Physical functioning and quality of life after cancer rehabilitation. Int J Rehabil Res. 2004;27(1):27-35.

6. Lin YH, Pan PJ. The use of rehabilitation among patients with breast cancer: a retrospective longitudinal cohort study. BMC Health Serv Res. 2012;12:282.

7. International Association for the Study of Pain. Task Force on Taxonomy - Classification of Chronic Pain: descriptions of chronic pain syndromes and definition of pain terms. 2nd ed. Seattle: IASP Press; 1994.

8. DeSantana JM, Walsh DM, Vance C, Rakel RN, Sluka KA. Effectiveness of transcutaneous electrical nerve stimulation for treatment of hyperalgesia and pain. Curr Rheumatol Rep. 2008;10(6):492-9.

9. Somers DL, Clemente FR. Transcutaneous electrical nerve stimulation for the management of neuropathic pain: the effects of frequency and electrode position on prevention of allodynia in a rat model of complex regional pain syndrome type II. Phys Ther. 2006;86(5):698-709. 
10. Johnson MI, Bjordal JM. Transcutaneous electrical nerve stimulation for the management of painful conditions: focus on neuropathic pain. Expert Rev Neurother. 2011;11(5):735-53.

11. Yameen F, Shahbaz NH, Hasan Y, Fauz R, Abdullah M. Efficacy of transcutaneous electrical nerve stimulation and its different modes in patients with trigeminal neuralgia. J Pak Med Assoc. 2011;61(5):437-9.

12. Stein C, Eibel B, Sbruzzi G, Lago PD, Plentz RD. Electrical stimulation and electromagnetic field use in patients with diabetic neuropathy: systematic review and meta-analysis. Braz J Phys Ther. 2013;17(2):93-104.

13. Cheing GL, Luk ML. Transcutaneous electrical nerve stimulation for neuropathic pain. J Hand Surg Br. 2005;30(1):50-5.

14. Radhakrishnan R, King EW, Dickman JK, Herold CA, Johnston NF, Spurgin ML, et al. Spinal 5- $\mathrm{HT}_{2}$ and $5-\mathrm{HT}_{3}$ receptors mediate low, but not high, frequency TENS-induced antihyperalgesia in rats. Pain. 2003;105(1-2):205-13.

15. King EW, Audette K, Athman GA, Nguyen HO, Sluka KA, Fairbanks CA. Transcutaneous electrical nerve stimulation activates peripherally located alpha-2A adrenergic receptors. Pain. 2005;115(3):364-73.

16. Sabino GS, Santos CM, Francischi JN, Resende MA. Release of endogenous opioids following transcutaneous electric nerve stimulation in an experimental model of acute inflammatory pain. J Pain. 2008;9(2):157-63.

17. Whynes DK, McCahon RA, Ravenscroft A, Hodgkinson V, Evley R, Hardman JG. Responsiveness of the EQ-5D health-related quality-of-life instrument in assessing low back pain. Value Health. 2013;16(1):124-32.

18. Rett MT, Wardini EB, Santana JM, Mendonça ACR, Alves AT, Saleme CS. Female urinary incontinence: quality of life comparison on reproductive age and postmenopausal period. Fisioter Mov. 2016;29(1):71-8.

19. Rakel B, Cooper N, Adams HJ, Messer BR, Frey Law LA, Dannen DR, et al. A new transient sham TENS device allows for investigator blinding while delivering a true placebo treatment. J Pain. 2010;11(3):230-8.
20. Makluf ASD, Dias RC, Barra AA. Avaliação da qualidade de vida em mulheres com câncer de mama. Rev Bras Cancerol. 2006;52(1):49-58.

21. Perry S, Kowalski TL, Chang CH. Quality of life in women with breast cancer: benefits, acceptability and utilization. Health Qual Life Outcomes. 2007;5:24.

22. Perez DJ, Williams SM, Christensen EA, McGee RO, Campbell AV. A longitudinal study of health related quality of life and utility measures in patients with advanced breast cancer. Qual Life Res. 2001;10(7):587-93.

23. Rietman JS, Geertzen JH, Hoekstra HJ, Baas P, Dolsma WV, de Vries J, et al. Long term treatment related upper limb morbidity and quality of life after sentinel lymph node biopsy for stage I or II breast cancer. Eur J Surg Oncol. 2006;32(2):148-52.

24. Kootstra J, Hoekstra-Weebers JE, Rietman H, de Vries J, Baas P, Geertzen JH, et al. Quality of life after sentinel lymph node biopsy or axillary lymph node dissection in stage I/II breast cancer patients: a prospective longitudinal study. Ann Surg Oncol. 2008;15(9):2533-41.

25. Oliveira IS, Costa LC, Manzoni AC, Cabral CM. Assessment of the measurement properties of quality of life questionnaires in Brazilian women with breast cancer. Braz J Phys Ther. 2014;18(4):372-83.

26. Silva MD, Rett MT, Mendonça ACR, Silva Jr WM, Prado VM, DeSantana JM. Qualidade de Vida e Movimento do Ombro no Pós-Operatório de Câncer de Mama: um Enfoque da Fisioterapia. Rev Bras Cancerol. 2013;59(3):419-26.

27. Baptista AF, Gomes JRS, Oliveira JT, Santos SMG, Vannier-Santos MA, Martinez AMB. High and low-frequency transcutaneous electrical nerve stimulation delay sciatic nerve regeneration after crush lesion in the mouse. J Peripher Nerv Syst. 2008;13(1):71-80.

28. Somers DL, Clemente FR. Contralateral high or a combination of high- and low-frequency transcutaneous electrical nerve stimulation reduces mechanical allodynia and alters dorsal horn neurotransmitter content in neuropathic rats. J Pain. 2009;10(2):221-9. 
29. Мa YT, Sluka KA. Reduction in inflammationinduced sensitization of dorsal horn neurons by transcutaneous electrical nerve stimulation in anesthetized rats. Exp Brain Res. 2001;137(1):94-102.

30. Ornelas FA, Rodrigues JRP, Uemura G. Análise sensitiva convencional no pós-cirúrgico de câncer de mama. Rev Bras Mastologia. 2009;19(2):53-9.

31. Torresan RZ, Santos CC, Conde DM, Brenelli HB. Preservação do nervo intercostobraquial na linfadenectomia axilar por carcinoma de mama. Rev Bras Ginecol Obstet. 2002;24(4):221-6.
32. Pollo A, Amanzio M, Arslanian A, Casadio C, Maggi G, Benedetti F. Response expectancies in placebo analgesia and their clinical relevance. Pain. 2001;93(1):77-84.

Received in 04/29/2016

Recebido em 29/04/2016

Approved in 09/18/2017

Aprovado em 18/09/2017 